\title{
'The constant rejections hurt': Skills and personal attributes needed to successfully complete a thesis by publication
}

Margaret K. Merga, Edith Cowan University, m.merga@ecu.edu.au, ORCID: M. K. Merga: 00000002-9009-3700

Shannon Mason, Nagasaki University, shan@nagasaki-u.ac.jp, ORCID: S. Mason: 0000-0002-89994448

Julia E. Morris, Edith Cowan University, j.morris@ecu.edu.au, ORCID: J. Morris: 0000-0003-44818050

Key point/s:

- Completing a thesis by publication (TBP) may involve common challenges that can differentiate this approach from the traditional doctoral journey.

- TBP doctoral candidates may need specific skills and attributes to succeed.

- Editors, peer-reviewers and publishers are a key source of critical feedback that doctoral students will receive on the TBP journey.

- Through understanding of the specific skills and attributes TBP candidates need to succeed, critical feedback can be tailored to support achievement.

- Editors, peer-reviewers and publishers may also find themselves as gatekeepers of student completion through the TBP approach.

Abstract: The Thesis by Publication (TBP) is an increasingly popular approach to doctoral education that sees candidates publishing their research during their candidature, and include these outputs in their final thesis submission. Responsive to the realities of modern academia, a TBP provides doctoral candidates with opportunities to engage in the scholarly publication process, and to build their research portfolio. As the TBP gains further traction in many fields and countries, there is a need to better understand the skills and attributes needed to complete a TBP successfully. This paper draws on the views of 246 recent doctoral graduates of Australian universities to identify the skills and attributes they felt supported their success. Their responses have implications for the development and refinement of institutional policies and programs that are sensitive to the needs and experiences of doctoral candidates seeking to publish during candidature and create a TBP. As editors, peerreviewers and publishers see a growing influx of papers sole- or co-authored by doctoral candidates in response to the trend toward TBP, they may find themselves involved in supporting students to develop the skills and attributes needed to successfully publish during candidature.

Key words: Doctoral education, Thesis by Publication, student skills, student attributes, academic writing, scholarly publishing

\section{Introduction}

While the traditional thesis monograph still predominates as the preferred $\mathrm{PhD}$ output in most regions, the Thesis by Publication (TBP) is gaining traction. The TBP is known by many names, however for the purposes of this paper, we conceptualise it as a thesis typically including peer-reviewed research outputs (including journal articles, conference papers and other research texts) that are produced during candidature, and that are incorporated into an overarching work which will include linking elements, such as introduction, linking and conclusion materials (Mason \& Merga, 2018a; Robins \& Kanowski, 2008). Publication during candidature is 'a significant recruitment criteria in academe' (Jackson \& Michelson 2015, p. 1662), and one that can foster in students 'an increased sense of achievement during the course of their study and improved motivation in progressing to the next stage of their research' (Pickering \& Byrne, 2014, p. 535). Publishing during a $\mathrm{PhD}$ is associated with career success (Horta \& Santos, 2016), and a TBP may be perceived as more rigorous and relevant than the traditional monograph (Asongu \& Nwachukwu, 2017; Baverstock \& Wenger, 2018). Early doctoral students in Australia typically show 'awareness of the great value that universities supposedly attach to publications' even if they do not adopt the TBP pathway themselves (Mantai, 2017, p. 641).

This is the author manuscript accepted for publication and has undergone full peer review but has not been through the copyediting, typesetting, pagination and proofreading process, which may lead to differences between this version and the Version of Record. Please cite this article as doi: $10.1002 /$ leap.1245 
However, while the TBP becomes increasingly common (Hagen, 2010), 'those who currently embark on the TBP journey instead of the traditional route are still considered pioneers in some spaces where the TBP is not yet commonplace' (Mason, Merga \& Morris, in press). There is a paucity of current exact figures on the prevalence of this mode, as 'national data on university candidates do not extend to information regarding their mode of thesis, or details of publications within their thesis' (Mason, Merga \& Morris, in press). There are differences in prevalence of TBP mode across disciplines, and there is a great deal of variety in possible forms, as we have illustrated in previous analysis (Mason \& Merga, 2018a; Mason \& Merga, 2018b). While there is relatively limited current research in this space, in a recent analysis of 165 doctoral theses by publication in the humanities and social sciences, journal articles predominate as the most common publication type 'with almost $99 \%$ of all candidates including at least one journal article' (p. 146), though conference proceedings and book chapters are also included in $19 \%$ and $11 \%$ of these theses respectively. Within the same sample, 'a total of 750 publications were identified, ranging from one to 12 publications, and an average of 4.5 publications per thesis, and a mode of 4 publications' (p. 146), suggesting a lack of uniformity in the volume of incorporated publications.

Completing a $\mathrm{PhD}$ is a challenging process, and one that may be enhanced through the possession of certain skills and attributes. As noted by Alexander and Davis (2019), a 'PhD degree is by no means a homogeneous phenomenon. In fact, it differs in organisation, specification, duration, composition, prestige and quality control from one country to another, and indeed from one institution, or even one university department, to another' (p. 2-3). It will also vary between individuals in the same context, as there is no uniform doctoral journey, however institutions may seek to find commonalities and gaps in order to target their doctoral training programs to meet student needs, and to optimise completion rates. There is an increasingly articulated expectation that skills acquired during the doctoral journey have transferability in academia and beyond, with perhaps insufficient attention given to the quality of research training graduates receive and the research they produce (Cuthbert \& Molla, 2015). We contend that as there is no homogenous doctoral journey, skill acquisition should be best tailored toward aspirational vocational trajectories, and the skills and attributes needed will also ideally be responsive to the choice of thesis output. As little research focusses on the skills and personal attributes specifically needed by TBP oriented candidates, one way to enhance the training and outcomes of contemporary doctoral candidates is to learn more about skills and attributes they will need to draw upon to complete a $\mathrm{PhD}$ in the increasingly popular non-traditional TBP model.

This paper contributes to this goal through analysis of the views shared by 246 recent doctoral graduates who successfully completed a TBP in Australia on the skills and attributes they valued in the completion of their journey. We focus on both skills and attributes, as while it can be contended that skills are learned competencies (such as reading), attributes are personal qualities that may be more challenging to influence (such as resilience). While institutions will be interested in our findings as they can direct key competencies that need to be fostered early in the doctoral journey, prospective doctoral students will be more concerned with the personal attributes, as these may help to inform which journey best aligns with their extant attributes. While personal attributes are not immutable, and can be further developed, they are characteristics rather than learned skills, and are situated as part of the self, which is why they can be related to outcomes and tendencies (Jung \& Sosik, 2006). As editors, peer-reviewers and publishers may see a growing influx of papers sole- or co-authored by doctoral candidates in response to the trend toward TBP, they may find themselves, through the critical feedback they provide, involved in supporting students to develop the skills and attributes needed to successfully publish during candidature, and therefore complete using this doctoral mode.

\section{Materials and methods}

The qualitative data explored in this paper were collected from $\mathrm{PhD}$ graduates who successfully completed a TBP. Inclusion criteria ensured that only respondents who submitted a thesis including at 
least one academic publication were added to the sample. Due to a lack of available tools in this area, we developed and piloted a self-administered online survey, hosted in Google Forms. While the full exploratory survey included questions relating to an expansive array of objectives, this paper focuses on qualitative data collected through open fields in relation to the skills and attributes respondents felt contributed to their ability to achieve a TBP. While a survey tool is atypical for collection of qualitative data, where a sample is sought from a population that is broadly distributed and therefore inaccessible, it can be the only means by which to collect such data within resourcing constraints.

We sought to recruit respondents who had recently (2014-2018) successfully completed a TBP through an Australian university. As an initial step, Trove, the online repository of the National Library of Australia, and the Proquest dissertations \& theses database were searched for TBPs.

Subsequently, the online repositories of individual universities were searched, though this posed additional challenges as few such repositories clearly flagged TBPs within their collections, and access was also sometimes restricted beyond the institution. Key challenges in sample identification and thus recruitment also included 'the lack of a centralised database of doctoral theses in Australia', 'the lack of indexing of some universities concerning the mode of thesis', 'the non-inclusion of contact details in many doctoral theses', and 'the movement of Australian doctoral graduates into various positions in Australia and around the world, not all of which result in their professional contact details being publicly available' (Mason, Merga \& Morris, in press).

Despite these challenges, these searches yielded 1,586 doctoral graduates who had produced a TBP. The name, institutional affiliation and field of study were noted for each potential respondent, and this information was used to attempt to find contact email addresses. These were sometimes sourced in university staff profiles, or in recent publications. Of the 1,586 identified parties, email addresses for only 880 could be sourced through this investigation. We sought to further expand this pool by leveraging other forms of social media as potential access points. We attempted to contact 578 candidates through ResearchGate, Twitter profiles, contact forms on professional and personal websites, Facebook, and Academia.

We also promoted the survey during the same period through contacts with the graduate schools of 41 universities offering a PhD program in Australia and promotion across Facebook, Twitter and ResearchGate. We encouraged interested parties to onshare the details to recruit possible participants through snowball sampling. Data were collected from September 2018 to January 2019.

While the full exploratory survey included questions relating to an expansive array of objectives, this paper focuses on qualitative data collected through open fields in relation to the skills and attributes respondents felt contributed to their ability to achieve a TBP.

The specific questions asked were as follows:

A. What skills do you feel are needed to complete a Thesis by Publication?

B. What personal attributes do you feel are needed to complete a Thesis by Publication?

Recurring thematic codes were identified in the resultant data, and refined using a process of constant comparative analysis (Boeije, 2002; Kolb, 2012). We employed 'a process of constant rereading, with labelling tentatively applied, discarded and refined constantly during this process', similar to our treatment of previous qualitative data obtained through surveys (Merga, 2017, p. 149). The constant comparative method was designed to support analysts seeking to generate theory and findings which are 'integrated, consistent, plausible, close to the data' (Glaser, 1965, pp. 437-438). However, we were also responsive to Deterding and Waters' (2018) contemporary vision of flexible coding of large qualitative data sets, using key aspects of their method such as indexing to manage the substantial volume of data, and we brought to bear our current knowledge in this field. As contended by Deterding and Waters (2018), while contemporary qualitative researchers acknowledge earlier seminal works, in reality we tend not to employ the purely inductive approaches previously 
outlined by Glaser and others. As such, we followed an abductive approach in analysis, which 'rests on the cultivation of anomalous and surprising empirical findings against a background of multiple existing sociological theories and through systematic methodological analysis' (Timmermans \& Tavory, 2012, 169). We used NVivo qualitative software package to support our analysis. This exploratory qualitative approach is necessary as so little is known about the skills and attributes needed to complete a TBP journey according to successful past candidates, and while the approach lacks statistical-probabilistic generalizability, the rich detail afforded by this approach constitutes essential foundation work, optimizing the opportunities afforded by the qualitative approach (Smith, 2018). We also note that findings do not relate to the viva or oral defence of the thesis process, as 'oral examinations are not part of our protocols' (Brabazon, 2013) in Australia, though this may be shifting in recent times. While the subjectivity of self-report is a limitation of this research, courtesy bias is unlikely to have influenced responses, as responses were anonymous, collected remotely via survey, and in most cases, the researchers unlikely to be personally known by the respondents.

\section{Results and discussion}

Our final data set included responses from 246 recent doctoral graduates from 35 different Australian universities, and a wide range of research fields. While their responses conformed to our expected disparate experiences and disciplines, delivering the expected broad variation in the $\mathrm{PhD}$ journey, certain key themes strongly recurred within the data as we detail herein. Pseudonyms have been used to preserve anonymity, and we have decided to use them consistently across the papers produced from this research so that participants can locate themselves within the research. We present results and discussion concurrently, as is acceptable in presentation on qualitative findings, to allow readers to examine where our results sit in relation to extant literature. It can be contended that these two sections are often usefully combined, as readers can make sense of results more readily with support from accompanying interpretation (Doumont, 2010).

\section{Skills for successful completion of a TBP \\ Collaboration and interpersonal skills}

The focus on collaboration and interpersonal skills in this data set encompassed supervisory relationships, but also management and leadership in broader research teams. Respondents felt collaboration and related interpersonal skills were beneficial for achieving a TBP, positioning 'good communication and delegation of tasks among the student and supervisors', 'ability to work collaboratively with others' and 'skills to manage interests from different parties' as beneficial. These skills could offer benefits for conducting and publishing their research. Networking and leadership were also identified within this code, with respondents discussing the importance of knowing 'how to network, how to best leverage networks and other peoples' skill sets to learn from each other', and 'knowing how to organise co-authors and lead a team of authors.' Sensitivity to extant power strata within universities was also highlighted as a valuable skill by Hattice, who noted the benefits of 'an understanding of very complex dynamics and power-imbalances within the university environment', as 'lack of experience in this regard can be exploited by others very easily'.

It can be contended that 'completing a TBP enables learners to swiftly enter their field, opening up possibilities for international discussion and collaboration' (Merga, 2015, p. 295). From these results, it is apparent that interpersonal and collaborative skills have transferrable benefits beyond doctoral candidature, into academia where such skills are essential to join the academic community and work in research teams. However, in the context of the current emphasis on the PhD experience fostering a transferrable skill-set, it is also noteworthy that these skills are vital beyond academia, and offer benefit across a range of industries, as well as being a staple in many job advertisements, with the related teamwork, communication and interpersonal skills in demand by employers (Bennett, 2002). It must also be recognised that for doctoral candidates and early career researchers, these collaborations can require strong collaborative skills that are further complicated by uneven power differentials, as 'many work in research groups where the need to consider the wishes of others 
whose favours they need to win' (Nicholas et al., 2017), and doctoral students may need mentoring and support to negotiate these relationships with agility and resilience.

\section{Academic writing \\ Writing skills strongly recurred as essential for student achievement in a TBP approach. Ioan emphasised}

proficiency with language use; $\ldots$ ability to create a story that aims at filling gaps/pushing the knowledge, but, at the same time, has potential to interesting/attracting readers, i.e., why should people, in the first place, read this research-piece? How to emerge from the jungle of many good papers that are out there?

loan's focus on writing for audience engagement as well as information showed close consideration of the dissemination purpose of academic journal writing. Audience was also important to Shelley, who highlighted the value in

the ability to adapt your argument to different audiences based on the journal or book etc., strong persuasion skills based on evidence i.e. the ability to craft a persuasive argument based on cutting-edge evidence, ability to seek out opportunities and make your own where none exists/entrepreneurship.

The importance of situating writing within field knowledge and norms was emphasised by Joel, who noted that 'you need to know how to write papers for your chosen field', and that 'for scientific publications, this is writing concise, but critical evaluations of the prior literature and the findings of the present study.' Style and voice emerged as key preoccupations, with Shane explaining that what was needed was 'not just good writing skills, but the specific kind of dry-but-interesting writing required in order for reviewers to approve it.'

Before more advanced skills could be displayed, candidates felt they needed a sound base proficiency. Jess noted the value in 'being able to write adequately in English. I reviewed papers that had such poor spelling and grammar that they were burdensome to review and had to go through more rounds of review than necessary for well written papers', with Constance also noting that 'writing skills (language, style, grammar, etc.) are critical - for me, it was learning to write clearly and succinctly for a scientific audience'.

Writing is not just a vital skill for TBP production. Traditional theses are also strongly reliant on this skill, with Catterall et al. (2011) noting

concerns that the quality of student writing may affect completion were most often expressed in relation to the constraints around candidature time. For example, one supervisor believed that 'due to the pressure of the three-year $\mathrm{PhD}$, developing the writing skills of students during this time is nearly impossible.' For several supervisors, this pressure meant taking more ownership of student writing than they would have liked (Catterall et al., 2011, p. 13).

However, while strong writing can be considered an essential skill across the board for thesis production, TBP candidates need strong writing skills, confidence in writing, and ability to manipulate their authorial voice to meet the needs of diverse outlets and audiences (Merga, 2015), skills clearly valued by this sample.

\section{Publication journey negotiation}

Negotiating the publication journey can be a complex and demanding experience (Merga, Mason \& Morris, 2018), and the respondents identified skills in this area as beneficial for their progress. 
Respondents described the importance of 'understanding publication requirements (each journal has their own)', and having 'a good understanding of the professional/industry modes of presenting research information/results - including preferred journals'. As such, candidates did not just need to possess 'knowledge and understanding of the publication process and possible setbacks', as stated by one respondent, they also needed to understand how different publications were valued and measured within their research community. Part of this involved adoption of a realistic outlook, and 'skills to realistically assess journals and select ones appropriate to your research and expected audience - most papers do not belong in Nature'.

For some respondents, this skill set was isolated as the most important, or a key distinguishing point from the traditional approach. Chenglei noted that students benefited from 'all the things needed for a regular $\mathrm{PhD}$ plus all the things needed to deal with/wrangle publishers and journal editors'. Hamish expressed the following view:

I think experience with publication processes is crucial to TBP. Candidates need to fully understand review processes and what is needed before attempting a TBP PhD or I feel there is a lot of wasted time in getting up to speed.

However, the role of the supervisor as a conduit was also noted. Melanie explained that

I think that the skills of the supervisor are more important than the skills of the student, as long as the student is competent. It's important to have good guidance about the types of projects that can be published in good journals in reasonable time frames, and to help the student to develop the ability to write in the correct style to the appropriate standard.

In our previous work, we have noted that early career researchers, during both the processes of identifying appropriate journals and interacting with journals during the publication process, need to develop an understanding of 'hidden knowledge lying beyond the author guidelines, which needed to be negotiated to ensure successful publication' (Merga, Mason \& Morris, 2018, p. 384). Each phase of the publication journey involves drawing on what is for many an unfamiliar and complex skill set. For example, choosing a target journal at the outset may involve finding alignment with themes and methods, close reading of author guidelines, reading of sample articles from journals to adopt appropriate written voice and join an extant conversation, gaining familiarity with the journals' editorial boards, amongst numerous other strategic actions (Stoilescu \& McDougall, 2010). We contend that this skill set is particularly aligned with the TBP approach.

Dealing with peer-review and feedback

The peer-review process is a vital part of quality control in academia, and as one respondent noted 'candidates need to fully understand review processes and what is needed before attempting a TBP'. While 'previous experience in peer-reviewed publication' is seen as an advantage, for many candidates the TBP is their first opportunity to engage in the process, and developing an ability to 'deal with' or 'cope with' the process is highly valued. The process of review and feedback is one of the main ways in which the TBP deviates from the traditional approach, as explained by Carlos:

Papers will be judged by a different set of reviewers, who are unknown to you and your supervisor, each time. A traditional thesis, on the other hand, is only judged once, by reviewers that your supervisor selects.

During TBP candidature, feedback is received not only from supervisors, but also from a number of reviewers who are tasked with identifying shortcomings of papers, rejecting flawed research, and providing advice to authors of papers with publication potential (Guthrie, Parker, \& Dumay, 2015). 
Each reviewer will look at a manuscript through the lens of their own perspectives, as well as the scope and requirements of the journal. Shelley described benefit in 'the ability to be flexible with your thinking and integrate diverse viewpoints into your own ... an essential part of the peer review process'. Academics at all stages of their careers experience negative feedback and/or rejection, and for doctoral students who are honing their skills, it is highly likely that they will face rejection during their candidature. Thus, respondents prize the capacity 'to deal with rejection and negative peer review comments without falling apart', and to 'handle rejection and criticism from reviewers and not let it de-rail your entire study'.

While 'the constant rejections hurt', respondents advised a need to 'take criticism', and to develop a 'thick skin'. Perfection is an unattainable goal for all academics regardless of their level of experience, and aspiring to perfection is a predictor of academic stress and anxiety (Cowie, 2018). Doctoral candidates need to be supported so that inevitable rejections and criticism are not viewed as purely negative, but as a normal part of the process that can facilitate their further development as an academic. As noted by Rodriguez-Bravo et al. (2017), 'peer review can be seen as a form of schooling, which all ECRs have to endure in order to obtain security and to progress in their career' (p. 275).

\section{Organisation, planning and time management}

A TBP journey is undeniably typically a more complex endeavour than the traditional route, requiring high level organisation, planning and time management skills. As one respondent contended, 'project management skills are critical as one would need to manage several research papers/projects and co-authors within the candidature', a more complex endeavour than producing the traditional monograph. Time, and its careful management, becomes of essence in this context, with a respondent highlighting the importance of allocating time to revise an article 'while not falling behind with writing the other chapters/articles to complete the thesis', and being able to 'undertake concurrent tasks without being overwhelmed by the excessive workload.' This may be driven by publication and acceptance imperatives that reflect institutions TBP policies, with Niamh noting that what was required was

all the normal skills required for a normal $\mathrm{PhD}$ thesis, but perhaps better time management in terms of the time it takes to get publications through review and published. There doesn't seem much point doing a TBP if the majority, if not all the papers are either published or in press.

In this instance, Niamh highlights her belief that the TBP will be of limited worth if the contributing papers have not passed beyond the review phase into publication or production. Planning also related to TBP design, with a respondent highlighting the importance of 'being able to clearly define your research questions such that they represent individual papers that would add to the field in which you are working and are therefore publishable.' May similarly discussed the importance of a

...clear plan on which areas of your research are suitable for publication, how to find appropriate journals for your paper topics, mapping out how to collect the data required and mapping out (time and) approaches to analyse, how this fits with thesis timelines/milestones, which academic skills to focus on developing at which time point to maximise efficiency...

Planning was also needed in order to optimise cohesion in the thesis. Zora focussed on the importance of managing diverse articles, noting that 'my articles were quite different in nature and this was somewhat challenging to bring together'. 
Organisation, planning and time management skills may be particularly pertinent for TBP candidates as delays beyond the control of the candidate are inherent in the publication journey. As noted by Mason (2018), turnaround times for publication are growing for a Thesis with Publication (TWP), and

this can impact a student's ability to complete their thesis in a timely manner. Universities have different policies regarding the status of papers permitted in the TWP. While some require papers to be published or in-press, others allow papers to be under review or papers which have been prepared for submission (p. 1233).

As such, possession of these skills, or willingness to focus on their acquisition, may be essential for TBP candidate success.

Information Technology (IT) proficiency

A final notable skill that was regarded among respondents relates to 'high level IT skills'. The need to understand certain software programs was cited as useful in the development of papers. Ayla suggested that candidates 'need to be proficient in the use of Word, Endnote, Illustrator etc. so papers and figures can be as professional as possible with limited input from supervisors.' Others recommended bibliographic software 'to streamline the research process and translation to manuscript writing', and Acrobat and Illustrator to assist in the development of the final thesis, because 'it is difficult to combine PDF articles and word docs and signed forms all into one, with correct page numbering etc.'

Indeed, IT plays a role within all of our earlier themes. From communicating with others through online media, writing and formatting papers, submitting and managing manuscripts through online portals, and organising candidates' time and resources, there are multiple tools that can potentially assist doctoral candidates. The skill lies in knowing how to select the most appropriate tools, and how to use them effectively. In developing this knowledge, institutions are ideally placed to provide training in this area. This finding also highlights the importance of further research to explore the level of digital literacy needed by TBP candidates, and to determine the kinds of tools that candidates may need additional support in to support timely completion.

\section{Attributes to support TBP completion}

Though organisation featured strongly in these responses, as it has already been explored as a skill, it is not duplicated here.

\section{Resilience and patience}

Resilience is a strongly recurring theme across the responses, and is seen as necessary particularly when dealing with the peer-review process, 'which can seem daunting, frustrating and harsh at times'. According to Zora, 'a student needs to be resilient, because of the harshness of the publication process. Reviewers can be challenging, and a student needs to be able to take this criticism'. For the TBP candidate, critical reviews of their work occur more regularly and 'earlier than [for] some traditional thesis candidates.' While this exposure and experience can present an opportunity for students to develop their resiliency (Merga, 2015), there are dangers when a student lacks resilience, particularly in the early stages of a candidature when they are still developing their identity as researchers. Hamish warned of the possible impact of criticism on fledgling researchers.

The ability to handle criticism is important for thesis by publication; for each peer-reviewed publication you will receive at least 3 critical reviews (co-authors, 2 peer-reviews). I have seen this demotivate many students to the point where their progress stagnates.

Further, the feedback and its delivery in the typically blinded peer-review process is not tailored specifically to beginner researchers, as advice from a supervisor might be. It means that feedback at times may be 'harsh', an adjective used by a number of participants to describe some of the feedback 
they received. Studies have suggested that a lack of resilience has contributed to 'the high prevalence rate of psychological distress' among higher education students (Stallman, 2011, p. 130). While this is true for all doctoral students, particular care is needed to ensure that those adopting a TBP have the resilience to cope with the peer-review process.

Alongside resilience, patience is also needed to overcome frustrations with the time necessary to complete the doctoral journey. Despite some universities' attempts to decrease thesis completion times, completing an original research project is a considerable task, on top of the requirement of publishing scholarly papers. As Autumn noted, 'patience [is necessary] especially if you receive rejection or very slow turnaround times from journals - both of which happened to me'. Completing a $\mathrm{PhD}$ is a long-term goal, the achievement of which is rarely smooth. Unlike those adopting a traditional approach, students are impacted heavily by the peer-review process. Further, turnaround times, over which students have no control, are notoriously slow in many fields (Powell, 2016). Thus, both patience and resilience are vital attributes to overcome the challenges inherent in completing a TBP. However, institutional policies must also have flexibility to respond to the time demands of the publication process.

\section{Determination, focus and passion}

Like any thesis, a major factor in successful completion is determination. As noted by Constance, the key is 'to keep the end goal in sight and keep working towards it'. Completing a TBP 'involves iterations of intense writing, responding to reviews, making amendments, copyediting, and proofreading, with each cycle resulting in a completed product, and thus a sense of completion' (Robins \& Kanowski, 2008). As a result, it may be easier for the TBP candidate to retain their focus, because the journey is broken down into smaller pieces.

Not only is there a need for a strong determination and focus on the goal of completing a PhD, but also specifically on the completion of a TBP. As a non-traditional approach, as contended by Marshall 'rebelliousness against the "old academia"' may be necessary. As Akane explains, there is a need for 'tenacity and to be able to ignore colleagues who consider this method not as rigorous as [the] traditional thesis'.

Mitchell felt the following attributes were of value on his TBP journey.

I think this method best suits those students who are wanting to establish an academic career after submission ... foresight to the career to be undertaken. If an academic career is what one is looking for after completion of $\mathrm{PhD}$, then TBP provides a right platform in terms of having a publication record to embark on a postdoctoral/faculty position.

Keeping focused and passionate for the years of doctoral study may be dependent on candidate's personal motivations for selecting the TBP approach, and their focus on future goals. Because it is more responsive to the needs of those who wish to enter or sustain an academic career, the TBP may better facilitate this academic vocational goal-oriented motivation, although this is an area in need of further research.

\section{Independence and assertiveness}

Students described the importance of being able to draw upon the resources of independence and assertiveness to be autonomous, faithful to their research direction, and advocate for their research vision. Respondents described the value of being 'capable of thinking for yourself', exhibiting 'assertiveness to stand your ground on decisions in a group of more experienced researchers'. This assertiveness was deemed necessary 'because supervisors don't always agree and collaborators can be lazy!'

An independent orientation was often positioned as essential for success. Sophia explained that 'I 
think I was able to do this because I work very independently and can figure things out on my own'. Similarly, Gina explained the importance of

genuine belief in the concept from the outset i.e. not being prejudiced against it because of a lack of understanding (or feeling forced to do it), being able to work despite the fear and selfdoubt, understanding the need to constantly recommit (the same with any $\mathrm{PhD}$ ), seeing your journey as one shared by many before you (rather than unique to you and that you are suffering more than others before you), an ability and willingness to embrace working independently without guidance and/or reliance on supervisors.

This commitment to independence and adhering to a unique vision that could not be dampened by external influences enabled students to overcome adversity in their journey. Macy noted that

in the end, you have to be there for yourself, even when everyone and anyone isn't available, or doesn't care, or is even trying to stop you, even when they don't give you the final write up money, and everyone else is moving faster and working happily in a group, even when they give your job to someone younger and prettier, even when your husband is jealous that you spend more time writing than being with him, even when the kids whine, 'Aren't you finished yet?' You just keep on. And one day, amazingly, it is done.

While some respondents in this study clearly had relationships with their supervisors that could be characterised as high dependency, others (for whatever reason) seemed to be operating with a high degree of autonomy, drawing on assertiveness to maintain their direction. Elsewhere we have explored the role of TBP in creating an autonomous researcher in relation to our own TBP:

Though I recognise that the degree of relinquishment of didactic support and subsequent and increased student autonomy will be highly variable, depending on the individuals concerned and the field, amongst other factors, I cannot sufficiently stress how empowering it was to find myself in a position of high autonomy in my research journey (Merga, 2015, p. 299).

Research supports the contention that supervisory support of student autonomy can result in greater student self-efficacy. Overall, Deane, and Peterson (2011) note that

The more supervisors supported students' autonomy, the greater students' selfefficacy in completing a range of research tasks including collecting and analysing data, writing research articles and integrating their results with the literature. This does not suggest a completely hands-off approach is desirable. Students with the highest research self-efficacy were those that reported their supervisors gave high levels of autonomy support and were also available to provide task-related help. (p. 802)

Therefore, this may be an attribute that can be shaped to some extent by a balanced supervisory approach that fosters autonomy while still retaining accessibility.

Introspection, adaptability and openness to self-improvement

While there is little work focussing on doctoral candidates' willingness to embrace their journey as an opportunity for learning and self-improvement, many supervisors recount experiences of working with intractable students, suggesting that this attribute is not a given in all doctoral students. This is problematic because a highly 'negative emotional response from students to sound supervisory feedback can disrupt doctoral learning' (Carter \& Kumar, 2017). The TBP journey, with its numerous opportunities for feedback beyond the supervisory dyad, also constitutes numerous opportunities for self-improvement and learning if students are willing to embrace them, and it requires a flexible and adaptable mind-set, which may pose a challenge for control-orientated researchers. 
Respondents noted that it is important that candidates are 'open to criticism', and that they 'take on board constructive criticism' and accept 'direction from more experienced authors'. As such, criticism should be viewed in a positive light, 'as a good experience to improve oneself.' 'Flexibility' and 'reflexivity' can serve to bring improvements to 'writing style, structure and content'. Considering the advice of others and adapting accordingly 'is important when finding ways to improve one's research and increase the chances for publication acceptance'. Constance ascribed value to the ability not only to listen to and accept advice, but also to appreciate that advice.

Being open and positive to receiving critical feedback and receiving that feedback as a positive contribution to your work. A reviewer has given up their time to provide thoughtful and, usually, constructive, feedback to enable the work to be published.

The flexibility means that at times students may need to make compromises in response to critical feedback. Kira suggested there may be times when you need 'to delete bits that you really love' but she also exhibited flexibility and positivity in suggesting that 'those bits' could be saved for a future article. Candidates may need to 'swallow their ego', and 'respond impartially to peer review which may be highly critical'.

Higher education reform internationally has focused on shifting the conceptualisation of the doctorate from a product to a process. However, within this paradigm there is often a focus on the process of skill development, both those required in academia, as well as other transferrable skills which are valued more broadly in labour markets (Bao, Kehm, \& Ma, 2016). What is perhaps also needed, is an acknowledgement of the attributes that are evident in successful doctoral graduates and the contribution that those attributes can make, not just to academia and other labour markets, but which are valued in society more broadly.

\section{Conclusion}

While we present skills and attributes separately in this paper, we acknowledge their interrelationships. The intersections between the codes are notable, and point to collocation in skills and attributes needed for TBP success. For instance, organisation was noted as both a skill and attribute by the TBP candidates in terms of being an extant attribute that also developed over the doctoral journey. The skill of being responsive to peer-review was supported by the attributes of resilience and patience. Introspection, adaptability and openness to self-improvement can also feed into developing skills to succeed in both TBP and future careers, as Can (2009) reported that doctoral students who are resistant to critical feedback are potentially more reluctant to seek feedback in the future, limiting their opportunities for growth.

As a key source of this critical feedback that doctoral students will receive on the TBP journey, publishers may find themselves shaping students' outputs, with critical feedback shaping both papers and subsequently the thesis that the paper is part of. They will also find themselves, through their acceptance and rejection of works intended for inclusion in the doctorate, gatekeepers for doctoral completion, as without the papers that contribute to the TBP, doctoral candidates may fail to complete, or need to revert to the traditional model. As such, we contend that it is absolutely crucial that publishers are explicit in their direct feedback, and the feedback that they mediate from peerreviewers, in order to support doctoral candidate development of the key skills outlined in this paper. Publication journey negotiation featured throughout the skills described by TBP candidates as a skill that is necessary for success in early career academia, and as we have previous contended, editorial boards, peer-reviewers and academic publishing teams can play a key role in supporting the achievement and learning of inexperienced academics (Merga, Mason \& Morris, 2018). We note that doctoral journey negotiation is supported by attributes of resilience and patience; and introspection, adaptability and openness to self-improvement, and TBP candidates explained how they developed skills of negotiation for the publication journey, but also for meeting the broader demands of research and academic life, as they worked with a range of people, including supervisors, research teams, 
reviewers and editors to develop transferrable skills from the doctoral journey (Cuthbert \& Molla, 2015). As such, while the TBP journey can enhance an individual's capacity to develop skills and attributes to succeed in academia as we have contended previously, many of the skills and attributes we have explored in this paper have clear, transferrable benefit beyond academia, aligning with the imperative that the doctoral journey foster capacity and vocational possibilities beyond the academic context. We also note that students clearly locate peer-reviewers, editorial boards and teams as central to this skill development.

Our findings have broad utility. They can support the development and refinement of institutional policies and programs that are sensitive to the needs and experiences of doctoral candidates. For example, the list of skills and attributes from these data can support the induction process for doctoral candidates within universities based on the collective voice of the successful candidates in this paper. As stated, the attributes are to some degree innate, and can be used by students to determine if the TBP is the right pathway for them. However, as skills are developed over time, universities can intervene in their doctoral candidates' learning and direct the development of explicit professional learning to support candidates as they navigate the complexities of the TBP journey (Merga, 2015). Supervisors may also consider these findings when seeking to advise students about optimal pathways to completion for their needs, and to match students with learning opportunities to foster key skills if they pursue the TBP approach. Both current and prospective doctoral candidates who are interested in the TBP approach can use the findings to both identify and develop their capacities in relation to both skills and attributes, but also to identify which of their own attributes are unlikely to be malleable. For example, if a prospective candidate knows that time management is not a quality they have, or are really interested in fostering, the TBP pathway may be inadvisable. This paper can help students to have realistic expectations of what the TBP journey involves.

While there were aforementioned challenges in recruiting doctoral candidates for this study, the resultant analysis from 246 Australian doctoral candidates provides opportunities for further research. For instance, the skills and attributes could be utilised to develop quantitative measures that explore a candidate's aptitude to undertake a TBP or to tailor learning experiences during their candidature. Research comparing the skills and attributes of TBP, exegesis and traditional thesis candidates could strengthen universities' advice for future doctoral candidates, and could include exploring concepts such as improved motivation to complete within the TBP population.

While it is not possible for respondents to compare these skills and attributes with those of the traditional model, as they typically would only have first-hand experience of the TBP journey, many respondents tried to distinguish their experience with what they felt was experienced by peers embarking on the traditional route. A doctoral journey distinguished by 'constant rejections' as per the title is far more likely to be experienced in the TBP context, where the gauntlet of the publication process is run, than the traditional thesis journey. As such, further research should seek to tease out the differences in skills and attributes between modes by recruiting respondents with TBP experience, as well as those with traditional thesis experience, to allow for critical examination of commonalities and differences. We also wonder if the growing popularity of the TBP will mean that publishers will receive more articles from inexperienced authors. Currently sole authorship by the doctoral candidate is comparatively rare and most co-author articles with experienced supervisors (Mason \& Merga, 2018b). However further research needs to be done to explore if the participation of inexperienced authors is increasing the number of papers that require significant revisions. It would also be pertinent to conduct further research exploring the extent to which doctoral candidates who lack the skills and attributes explored in this paper find themselves adopting questionable practices as a result of pressure to publish.

\section{References}

Alexander, D. E., \& Davis, I. R. (2019). The PhD system under pressure: an examiner's viewpoint. Quality Assurance in Education, 27(1), 2-12. 
Asongu, S. A., \& Nwachukwu, J. C. (2018). PhD by publication as an argument for innovation and technology transfer: With emphasis on Africa. Higher Education Quarterly, 72(1), 15-28.

Bao, Y., Kehm, B. M., \& Ma, Y. (2018). From product to process. The reform of doctoral education in Europe and China. Studies in Higher Education, 43(3), 524-541.

Baverstock, A., \& Wenger, D. (2018). What value do academic qualifications have within a professionoriented discipline?. Journalism Education, 6(3), 72-84.

Bennett, R. (2002). Employers' demands for personal transferable skills in graduates: A content analysis of 1000 job advertisements and an associated empirical study. Journal of Vocational Education and training, 54(4), 457-476.

Boeije, H. (2002). A purposeful approach to the constant comparative method in the analysis of qualitative interviews. Quality and Quantity, 36(4), 391-409.

Brabazon, T. (2013). In defence of the viva. The Australian. Retrieved from https://www.theaustralian.com.au/higher-education/opinion/in-defence-of-the- viva/newsstory/bd97fb42792be52d54d7c521c6c90889

Can, G. (2009). A model for doctoral students' perception and attitudes toward written feedback for academic writing. All graduate theses and dissertations, Paper 227, Utah State University. Retrieved from http://digitalcommons.usu.edu/etd/227

Carter, S., \& Kumar, V. (2017). 'Ignoring me is part of learning': Supervisory feedback on doctoral writing. Innovations in Education and Teaching International, 54(1), 68-75.

Catterall, J., Ross, P., Aitchison, C., \& Burgin, S. (2011). Pedagogical approaches that facilitate writing in postgraduate research candidature in science and technology. Journal of University Teaching \& Learning Practice, 8(2), 7-19.

Cowie, M. E., Nealis, L. J., Sherry, S. B., Hewitt, P. L., \& Flett, G. L. (2018). Perfectionism and academic difficulties in graduate students: Testing incremental prediction and gender moderation. Personality and Individual Differences, 123, 223-228.

Cuthbert, D., \& Molla, T. (2015). PhD crisis discourse: A critical approach to the framing of the problem and some Australian 'solutions'. Higher Education, 69(1), 33-53.

Deterding, N. M., \& Waters, M. C. (2018). Flexible coding of In-depth interviews: A twenty- first-century approach. Sociological Methods \& Research, ePrint before publication, retrieved from https://doi.org/10.1177/0049124118799377

Doumont, J. (Ed.) (2010). English communication for scientists. Cambridge, MA: NPG

Glaser, B. G. (1965). The constant comparative method of qualitative analysis. Social

Education 445.

Problems, 12(4), 436-

Guthrie, J., Parker, L. D., \& Dumay, J. (2015). Academic performance, publishing and peer peering into the twilight zone. Accounting, Auditing \& Accountability Journal, 28(1), 2-13.

Hagen, N.T. (2010). Deconstructing doctoral dissertations: How many papers does it take to make a PhD? Scientometrics, 85, 567-579.

Horta, H., \& Santos, J. M. (2016). The impact of publishing during PhD studies on career research publication, visibility, and collaborations. Research in Higher Education, $\quad$ 57(1), 28-50.

Jackson, D., \& Michelson, G. (2015). Factors influencing the employment of Australian PhD graduates. Studies in Higher Education, 40(9), 1660-1678.

Jung, D. \& Sosik, J. J. (2006). Who are the spellbinders? Identifying personal attributes of charismatic leaders. Journal of Leadership \& Organizational Studies, 12(4), 12-26.

Kolb, S.M. (2012). Grounded theory and the constant comparative method: Valid research strategies for educators. Journal of Emerging Trends in Educational Research and Policy Studies, (3)1, 83-86.

Mantai, L. (2017). Feeling like a researcher: Experiences of early doctoral students in Australia. Studies in Higher Education, 42(4), 636-650.

Mason, S. (2018). Publications in the doctoral thesis: challenges for doctoral candidates, supervisors, examiners and administrators. Higher Education Research \& Development, 37(6), 1231-1244.

Mason, S., \& Merga, M. (2018). A current view of the thesis by publication in the humanities and social sciences. International Journal of Doctoral Studies, 13, 139-155.

Mason, S., \& Merga, M. (2018a). Integrating publications in the social science doctoral thesis by publication. Higher Education Research \& Development, 37(7), 1454-1471.

Mason, S. Merga, M.K. \& Morris, J.E. (in press). Typical scope of time commitment and research outputs of Thesis by Publication in Australia. Higher Education Research \& Development.

Merga, M. K. (2015). Thesis by publication in education: An autoethnographic perspective for educational researchers. Issues in Educational Research, 25(3), 291-308.

Merga, M. K. (2017). What motivates avid readers to maintain a regular reading habit in adulthood?. Australian Journal of Language and Literacy, 40(2), 146-156. 
Merga, M. K., Mason, S., \& Morris, J. (2018). Early career experiences of navigating journal

article publication: Lessons learned using an autoethnographic approach. Learned

Publishing, 31(4), 381389.

Nicholas, D., Rodríguez-Bravo, B., Watkinson, A., Boukacem-Zeghmouri, C., Herman, E., Xu, J., ... \& Świgoń, M. (2017). Early career researchers and their publishing and authorship practices. Learned Publishing, 30(3), 205-217.

Overall, N. C., Deane, K. L., \& Peterson, E. R. (2011). Promoting doctoral students' research self-efficacy: Combining academic guidance with autonomy support. Higher Education Research \& Development, 30(6), 791-805.

Pickering, C., \& Byrne, J. (2014). The benefits of publishing systematic quantitative literature reviews for PhD candidates and other early-career researchers. Higher Education Research \& Development, 33(3), 534-548.

Powell, K. (2016). Does it take too long to publish research? Nature, 530(7589), 148-

Poyatos Matas, C. (2012). Doctoral education and skills development: An international

151. de Docencia Universitaria, 10(2): 163-191.

Robins, L., \& Kanowski, P. (2008). PhD by publication: a student's perspective. Journal of Research Practice, 4(2), 1-20.

Rodríguez-Bravo, B., Nicholas, D., Herman, E., Boukacem-Zeghmouri, C., Watkinson, A., Xu, J., ... \& Świgoń, M. (2017). Peer review: The experience and views of early career researchers. Learned Publishing, 30(4), 269-277.

Smith, B. (2018). Generalizability in qualitative research: Misunderstandings, opportunities recommendations for the sport and exercise sciences. Qualitative Research in Health, 10(1), 137-149.

Stallman, H.M. (2011). Embedding resilience within the tertiary curriculum: a feasibility Education Research \& Development, 30(2): 121-133.

Stoilescu, D., \& McDougall, D. (2010). Starting to publish academic research as a doctoral student. International Journal of Doctoral Studies, 5, 79-93.

Timmermans, S., \& Tavory, I. (2012). Theory construction in qualitative research: From grounded theory to abductive analysis. Sociological Theory, 30(3), 167-186. 


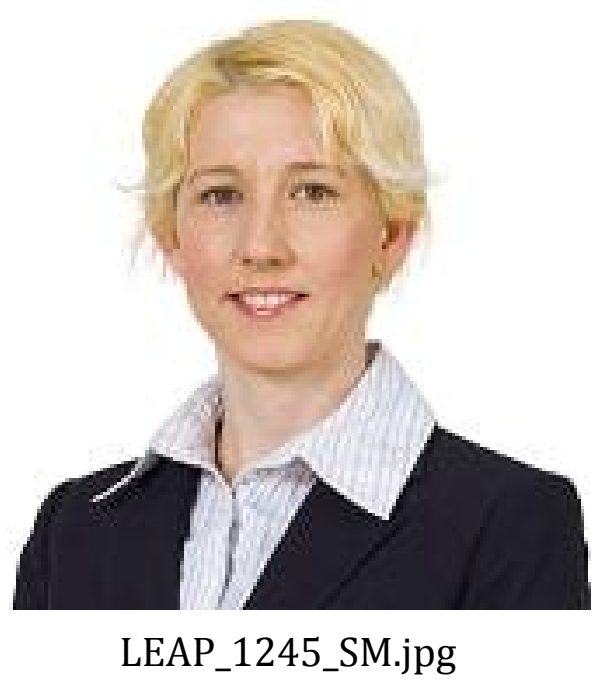

This article is protected by copyright. All rights reserved. 


\section{University Library}

\section{- M M N E R VA A gateway to Melbourne's research publications}

Minerva Access is the Institutional Repository of The University of Melbourne

Author/s:

Merga, MK;Mason, S;Morris, JE

Title:

'The constant rejections hurt': Skills and personal attributes needed to successfully complete a thesis by publication

Date:

2019-07-01

Citation:

Merga, M. K., Mason, S. \& Morris, J. E. (2019). 'The constant rejections hurt': Skills and personal attributes needed to successfully complete a thesis by publication. LEARNED PUBLISHING, 32 (3), pp.271-281. https://doi.org/10.1002/leap.1245.

Persistent Link:

http://hdl.handle.net/11343/286873 